\title{
Exposure of Anesthesiologists to Nitrous Oxide during Pediatric Anesthesia
}

\author{
Wushou Peter CHANG ${ }^{1 *}$, Chih-wen KAU ${ }^{1}$ and Shu-shya HSEU ${ }^{2}$ \\ 'Division of Environmental and Occupational Medicine, Institute of Public Health, School of Medicine, National \\ Yang Ming University, 155, Section 2, Lih-long Road, Shih-pai, Taipei, Taiwan \\ ${ }^{2}$ Department of Anesthesiology, Taipei Veteran General Hospital, Taipei, Taiwan
}

Received May 23, 1996 and accepted September 26, 1996

\begin{abstract}
Nitrous oxide $\left(\mathrm{N}_{2} \mathrm{O}\right)$ is one of the most common inhalation anesthetics in current anesthesiological practice. Even though artificial ventilation and active scavenging in operating theaters are employed in most of the modern hospitals, potential $\mathrm{N}_{2} \mathrm{O}$ contamination persists in regular anesthesia, particularly pediatric operation. In order to understand personal exposure during pediatric anesthesia, ambient monitoring for $\mathrm{N}_{2} \mathrm{O}$ exposure around the breathing zone of the anesthesiologist was conducted by a portable infra-red Miran $1 \mathrm{~B} 2$ spectrophotometer. The results demonstrated that general mask anesthesia generated greatest $\mathrm{N}_{2} \mathrm{O}$ contamination, with the mean time-weighted-average (TWA) concentrations of $85 \pm 48.4$ (mean \pm S.D.) ppm in 12 cases. Initial mask induction followed by cuffed endotracheal incubation ( 6 cases) or intravenous induction followed by uncuffed endotracheal intubation ( 6 cases) also produced significant pollution to the workers, with the mean TWAs of $33.2 \pm 24.0 \mathrm{ppm}$ and $31.9 \pm 18.0 \mathrm{ppm}$ respectively. These procedures provided exposure levels above the 25 ppm Recommended Exposure Limit (REL) of the National Institute of Occupational Safety and Health (NIOSH), U.S.A. ${ }^{1)}$ Modification with intravenous induction followed with cuffed endotracheal intubation or mask general anesthesia provided with a ventilation hood diminished the contamination apparently, with the resulting mean TWAs of $11.0 \pm 4.7 \mathrm{ppm}$ and 17.9 $\pm 9.8 \mathrm{ppm}$ in 7 and 5 cases respectively. The results indicated that excessive $\mathrm{N}_{2} \mathrm{O}$ exposure to anesthesiologists was not negligible during routine pediatric anesthesia. Significant reduction could be achieved via appropriate industrial modification.
\end{abstract}

Key words: Nitrous oxide, Anethetics, Pediatric, Anesthesia, Anesthesiologist, Exposure

\section{Introduction}

Exposure to trace concentrations of waste anesthetics has been considered hazardous for the anesthesiologists or surgical personnel since 1960s that adverse reproductive outcomes were observed in female workers in operating rooms ${ }^{2}$. Several epidemiological studies have further identified increased prevalence of renal and hepatic damage ${ }^{3)}$, infertility ${ }^{4)}$, reproductive difficulties ${ }^{5)}$, congenital anomalies and fetal growth retardation ${ }^{6}$ for those with occupational

*To whom correspondence should be addressed. anesthetic exposure. Increased sister chromatid exchange ${ }^{7}$, chromosomal aberrations ${ }^{8,9)}$ or DNA single strand breaks ${ }^{10}$ were also observed in the peripheral lymphocytes of those with occupational exposure to various anesthetics, including $\mathrm{N}_{2} \mathrm{O}$, halothane and isoflurane et al. Recently, we have also demonstrated that nurses in anesthetic department with chronic occupational $\mathrm{N}_{2} \mathrm{O}$ exposure carried significantly higher frequencies of cytogenetic damage; i.e., micronucleus in the lymphocytes than nurses without similar exposure ${ }^{11}$. A recommendation by the U.S. National Institute of Occupational Safety and Health (NIOSH) in 1977 suggested "control of nitrous oxide to a time-weighted average (TWA) 
concentration of $25 \mathrm{ppm}$ during the anesthetic administration period ${ }^{1)}$." In 1989, the American Conference of Governmental Industrial Hygienists (ACGIH) further recommended a $\mathrm{N}_{2} \mathrm{O}$ Threshold Limit Value (TLV) of 50 ppm for an 8-hour day ${ }^{12)}$ and an intermittent exposure level less than 150 ppm during $\mathrm{N}_{2} \mathrm{O}$ administration ${ }^{13}$. However, due to its easy and inexpensive application and lack of convenient or efficient monitoring in the workplace, $\mathrm{N}_{2} \mathrm{O}$ contamination persisted in anesthetic practices probably throughout the world ${ }^{14)}$.

Even though employment of active scavenging systems was introduced ${ }^{15,16)}$ and accompanied with improvement in anesthetic techniques and instrumentation ${ }^{17-21)}$, various anesthetic practices during dental ${ }^{22-24)}$ and veterinary surgeries ${ }^{25)}$ were still demonstrated to generate apparent ambient anesthetic exposure. Variation in manual technique has been claimed contributing to contamination during most adult anesthesia. These include face mask without tubing, poor fitting face mask, inappropriately sealed endotracheal tubing and so on. Some of these have been modified in practices for adult patients in recent years. For example, a mask accompanied with gas-scavenging system ${ }^{26)}$ was demonstrated to diminish $\mathrm{N}_{2} \mathrm{O}$ exposure for the anesthesiologists. However, there are some limitations for pediatric anesthesia and much of industrial modification has not been developed for this specific purpose.

This study was aimed to evaluate extensively the sources of $\mathrm{N}_{2} \mathrm{O}$ contamination to the anesthetic professionals during routine pediatric anesthesia by employing the Miran 1B2 portable infrared spectrophotometer. Attempts have also been made to understand the extent of $\mathrm{N}_{2} \mathrm{O}$ exposure during

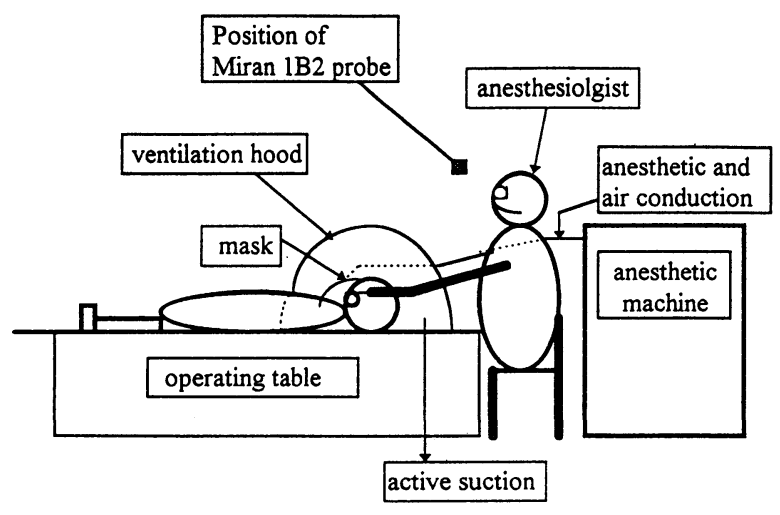

Fig. 1. Illustration of mask general anesthesia accompanied with a ventilation hood with active suction

The hood covers from the head to the upper chest of the child under anesthesia. various practices of pediatric anesthesia, meanwhile, a modified anesthesia with a local ventilation hood was elucidated for its effectiveness in reducing the pollution. The results evidenced significant $\mathrm{N}_{2} \mathrm{O}$ exposure in the breathing zone of the anesthesiologist while conducting pediatric anesthesia and provided caution for professionals working in the operating rooms.

\section{Material and Methods}

Several patterns of routine anesthesia in the anesthesiology department of the hospital under investigation were reviewed and five major pediatric general anesthesia were included for evaluation. These included general anesthesia with mask inhalation induction and maintenance (mask general anesthesia), mask induction followed by cuffed-endotracheal intubation, intravenous induction followed by cuffed- or uncuffed-endotracheal intubation, and mask general anesthesia with a modified ventilation hood (Fig. 1). The ventilation hood was a self-designed PVC tent (Fig. 2) which was provided with active suction offering negative pressure inside the tent and providing fresh air from exterior. The hood was fitted from head to upper chest of the patient and was transparent in composition that the anesthesiologists and surgeons can clearly see the patients. At least $6(\mathrm{~N} \geq 6)$ real-time whole course measurements were performed for each of the procedures, except in the mask general anesthesia

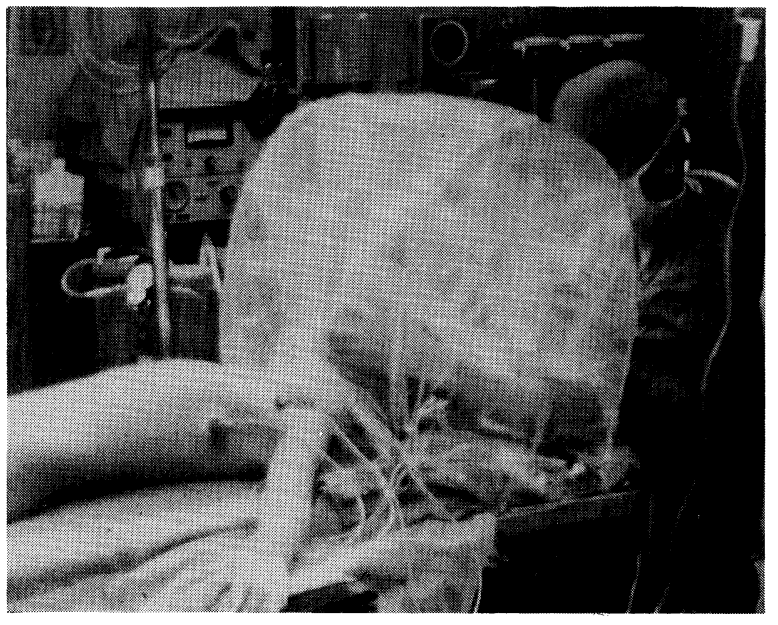

Fig. 2. A ventilation hood made of PVC and fit to the upper chest of the patient was illustrated

The hood carried active suction offering negative pressure inside the tent and providing fresh air from exterior and was transparent in composition that the anesthesiologists and surgeons can clearly see the patients. 
with a modified ventilation hood $(\mathrm{N}=5)$. One senior anesthesiologist was responsible for all the procedures and informed of the monitoring but, however, blinded to the results of measurement throughout the study period.

The breathing zone of the anesthesiologist at sitting position was defined as $1.2 \mathrm{~m}$ above ground level and within $30 \mathrm{~cm}$ from his or her face while in regular working position (Figs. 1 and 2). The tip of particulate filter on the Miran $1 \mathrm{~B} 2$ was placed in the respiratory zone of the anesthesiologist

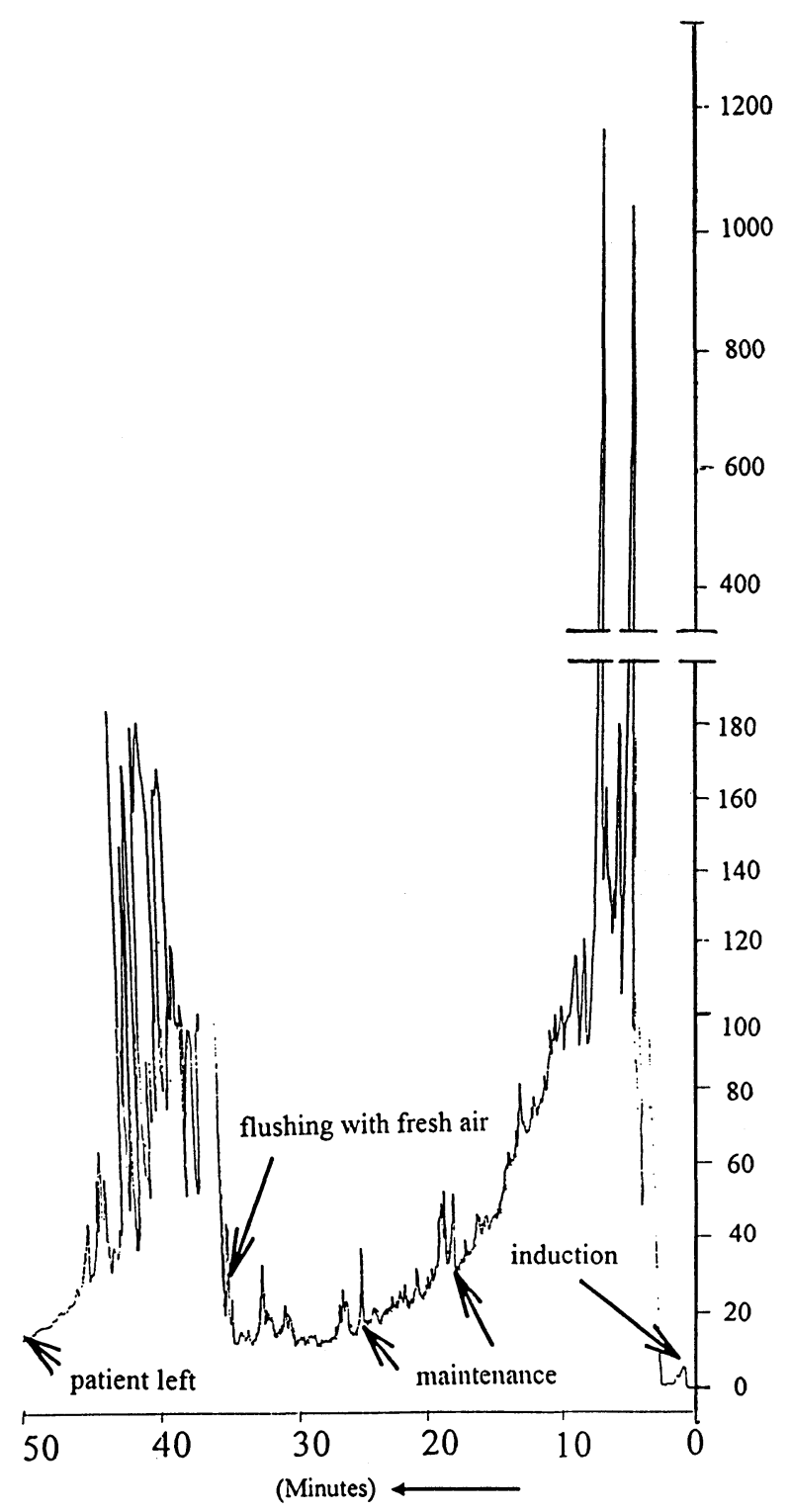

Fig. 3. Real time exposure measurements of $\mathrm{N}_{2} \mathrm{O}(\mathrm{ppm})$ in breathing zone of an anesthesiologist during the pediatric mask general anesthesia

Periods of induction, maintenance, flushing and patient leave are indicated (arrow). during measurement; i.e., from initial $\mathrm{N}_{2} \mathrm{O}$ influx from a low pressure anesthetic machine during induction until patient was removed from operating table. All the measurements were conducted on the first anesthesia or operation in the morning. This was to ensure negligible indoor $\mathrm{N}_{2} \mathrm{O}$ left; i.e., less than $0.5 \mathrm{ppm} \mathrm{N}_{2} \mathrm{O}$ detection limit by the Miran 1B2. The air exchange rate in all the operating theaters was maintained at 25 times per hour during the study period, as suggested ${ }^{25}$. All the anesthetic machines have been equipped with the Active Scavenging System (Ohmeda, U.S.A.) with closed reservoir and connected with the anesthetic machine before each data collection.

The measurement was conducted with the Miran 1B2 portable infrared spectrophotometer (Foxboro, Co., U.S.A.; calibrated to manufacturer's specifications) as described ${ }^{23}$. Briefly, the spectrophotometer was set to measure infrared absorbance of $\mathrm{N}_{2} \mathrm{O}$ at a wavelength of $4.54 \mu \mathrm{m}$ with a pathlength of $12.75 \mathrm{~m}$ at high range. The detection limit was $0.9 \mathrm{ppm}$, response time each $3 \mathrm{sec}$ and pump flow rate 25-30 1 per minute. Before beginning of measurement in each day, Miran 1B2 was calibrated with pure $\mathrm{N}_{2} \mathrm{O}$ gas (Scott Medical Product). The results were collected by a data logger and processed by software (Metrosonics Inc.) to acquire timeweighted average concentrations (TWAs) over the monitoring period. The results were presented as the mean TWA and 1 standard deviation for each anesthesia procedure.

\section{Results}

The real-time measurement of waste $\mathrm{N}_{2} \mathrm{O}$ concentrations around the breathing zone of the anesthesiologist during one pediatric mask general anesthesia was illustrated (Fig. 3). The duration of this procedure was 49 min, including 7.6 min of induction, $33.4 \mathrm{~min}$ of maintenance and $8 \mathrm{~min}$ of flushing before the patient was removed from the operating table. The TWA for the whole procedure was $84.5 \mathrm{ppm}$, with TWAs for the induction and flushing periods 306.9 ppm and $104 \mathrm{ppm}$ respectively. Significant fluctuation in $\mathrm{N}_{2} \mathrm{O}$ exposure was apparent during different periods of the procedure, particularly during induction and flushing. Peak concentrations of 1,181 and $180 \mathrm{ppm}$ was detected during the induction and flushing periods respectively. Severe contamination was not unusual in other mask general anesthesia practices. The mean TWA in 12 mask general anesthesia and those of another 4 different anesthetic procedures were illustrated in Table 1.

It was evident that procedures with mask general anesthesia, which were the most common pediatric anesthesia 
in this hospital and other hospitals in Taiwan, generated most $\mathrm{N}_{2} \mathrm{O}$ pollution in the breathing zone of the anesthesiologist. The mean TWAs ( \pm 1 S.D.) of $\mathrm{N}_{2} \mathrm{O}$ in 12 cases, $85.0 \pm 48.4$ $\mathrm{ppm}$, significantly increased over the recommended $25 \mathrm{ppm}$ by the $\mathrm{NIOSH}^{1)}$ and $50 \mathrm{ppm}$ by the $\mathrm{ACGIH}^{12)}$. It was contributed dominantly from $\mathrm{N}_{2} \mathrm{O}$ contamination during the periods "induction" and "flushing" and relatively less of the "maintenance," as shown in Table 2. The mean duration of induction and maintenance periods were $4.6 \pm 3.2 \mathrm{~min}$ and $36.7 \pm 3.7 \mathrm{~min}$ respectively in these 12 procedures, while the mean TWA concentrations $256.3 \pm 144.3$ and $51.8 \pm$ $25.1 \mathrm{ppm}$, respectively. The induction period was relatively short but more polluting than the maintenance periods, while the flushing period was much variable in duration. The induction period carried much higher $\mathrm{N}_{2} \mathrm{O}$ exposure that the peak $\mathrm{N}_{2} \mathrm{O}$ ranged from 213 to $3,929 \mathrm{ppm}$ in these 12 anesthesia. The mean of these peaks during induction was $1283.3 \pm 1278.9 \mathrm{ppm} . \mathrm{N}_{2} \mathrm{O}$ of 33 to $329 \mathrm{ppm}$ were noted during flushig periods in these 12 operations, with the mean of these peaks $192.7 \pm 95.4 \mathrm{ppm}$. During common practices, the ratios of $\mathrm{N}_{2} \mathrm{O}: \mathrm{O}_{2}$ supplied (L/min:L/min) were 6:2-3, $2: 2$ and $2: 2$ in these three periods respectively.
Mask induction followed by cuffed endotracheal intubation generated $\mathrm{N}_{2} \mathrm{O}$ contamination of $33.2 \pm 24.0 \mathrm{ppm}$ (TWAs) in 6 separate cases (Table 1). Anesthesia initiated by intravenous induction then replaced with uncuffed endotracheal intubation with caliber smaller than 5.0-6.0 $\mathrm{mm}$ in diameter were demonstrated with various degree of $\mathrm{N}_{2} \mathrm{O}$ pollution, the mean of TWAs $31.9 \pm 18.0 \mathrm{ppm}$ in 6 practices. Intravenous induction followed by cuffedendotracheal intubation apparently reduced the contamination and the mean of TWAs $11.0 \pm 4.7 \mathrm{ppm}$ in 7 practices. Finally, mask general anesthesia accompanied with a ventilation hood with local suction significantly reduced $\mathrm{N}_{2} \mathrm{O}$ contamination, the mean of the TWAs $17.9 \pm 9.8 \mathrm{ppm}$ in 5 practices.

\section{Discussion}

Various general anesthetic procedures for pediatric patients in this study were demonstrated to generate severe $\mathrm{N}_{2} \mathrm{O}$ pollution to the anesthesiologist. Among them, mask general anesthesia provided most severe exposure to the anesthesiologist (Table 1). As shown in Figure 3 and Table 2 , the induction periods were accompanied with most $\mathrm{N}_{2} \mathrm{O}$

Table 1. The mean time-weighted average $\mathrm{N}_{2} \mathrm{O}$ concentrations (TWA) pollution (ppm) to the anesthesiologist in 5 specific anesthesia.

\begin{tabular}{lcc}
\hline Anesthetic procedure & $\begin{array}{c}\text { Numbers of } \\
\text { measurement }\end{array}$ & $\begin{array}{c}\text { Mean TWA (ppm) during specific } \\
\text { procedures (mean } \pm \text { S.D.) }\end{array}$ \\
\hline $\begin{array}{l}\text { Mask General Anesthesia } \\
\begin{array}{l}\text { Mask induction followed by cuffed } \\
\text { endo-tracheal intubation }\end{array}\end{array}$ & 12 & $85.0 \pm 48.4$ \\
$\begin{array}{l}\text { Intravenous induction \& uncuffed } \\
\text { endotracheal intubation }\end{array}$ & 6 & $33.2 \pm 24.0$ \\
$\begin{array}{l}\text { Intravenous induction \& cuffed } \\
\text { endotracheal intubation }\end{array}$ & 6 & $31.9 \pm 18.0$ \\
$\begin{array}{l}\text { Mask anesthesia with } \\
\text { ventilation hood }\end{array}$ & 7 & $11.0 \pm 4.7$ \\
\hline
\end{tabular}

Numbers of measurement for each anesthesia were indicated.

Table 2. Mean duration and the $\mathrm{N}_{2} \mathrm{O}$ exposure (ppm) to the anesthesiologist during various periods in 12 mask general anesthesia (mean \pm 1 S.D.)

\begin{tabular}{lccc}
\hline Periods & Mean duration & $\begin{array}{c}\text { Mean concentration } \\
\text { (TWA; ppm) }\end{array}$ & $\begin{array}{c}\text { Extend/mean of peak } \\
\text { concentrations (ppm) }\end{array}$ \\
\hline Induction & $4.6 \pm 3.2 \mathrm{~min}$ & $256.3 \pm 144.3$ & $213 \sim 3929,1283.3 \pm 1278.9$ \\
Maintenance & $36.7 \pm 3.7 \mathrm{~min}$ & $51.8 \pm 25.1$ & $*$ \\
Flushing & $*$ & $*$ & $33 \sim 329,192.7 \pm 95.4$ \\
\hline
\end{tabular}

*: not determined due to great variation. 
pollution than the other periods. The induction period during mask general anesthesia spanned approximately 7.6 minutes (15 percent) of the whole specific procedure (Fig. 3) and average $4.6 \pm 3.2 \mathrm{~min}$ (10 percent) in these 12 anesthesia (Table 2) while it conferred more than half of the total $\mathrm{N}_{2} \mathrm{O}$ exposure in one general anesthesia to the anesthesiologist. Even though $\mathrm{N}_{2} \mathrm{O}$ administration during induction was relatively short in an 8-hour working day for an anesthesiologist, $\mathrm{N}_{2} \mathrm{O}$ exposure was apparently more than the short-term exposure limit of $150 \mathrm{ppm}$ suggested by the $\mathrm{ACGIH}^{12)}$. For an experienced anesthesiologist, more than 5 anesthetic procedures might be routinely expected in one working day. They would also receive more than [TWA 85 ppm in this study X 5 anesthesia/8 hour-day=TWA $53.1 \mathrm{ppm}]$ that recommended by the NIOSH${ }^{1)}$.

Several factors contributed to high exposure during the induction periods. First, $\mathrm{N}_{2} \mathrm{O}$ was usually employed with relatively higher concentration and mixed with oxygen in the inhalation inlet to the patients $\left(\mathrm{N}_{2} \mathrm{O}: \mathrm{O}_{2}=6 \mathrm{~L} / \mathrm{min}: 2-3 \mathrm{~L} /\right.$ $\mathrm{min}$ ) during the induction. This was intended to help smooth initial anesthesia for children. Second, the patient was not in complete sedation and it was difficult for the mask to fit these children's faces perfectly while he or she felt discomfort and moved their heads. Moreover, the anesthesiologists usually did not press the mask so tight against children's faces than on adult patients' and allow more $\mathrm{N}_{2} \mathrm{O}$ leak to ambient environment. Finally, the mask for children did not fit so well in design than those for adult patients. All these contributed to $\mathrm{N}_{2} \mathrm{O}$ leakage from margins of the masks, while mask anesthesia was seldom practiced in current adult anesthesia. Under such situation, the scavenging system usually was not able to diminish the pollution efficiently. If $\mathrm{N}_{2} \mathrm{O}$ leakage from masks could be enclosed during the induction period, as modified by the ventilation hood, the anesthesiologist would be much less exposed.

Mask general anesthesia followed by endotracheal cuffed intubation or intravenous induction followed by endotracheal intubation were shown to provide less $\mathrm{N}_{2} \mathrm{O}$ exposure. However, $\mathrm{N}_{2} \mathrm{O}$ leakage during mask induction before intubation would contribute significantly to the total exposure during the mask general anesthesia followed with cuffedintubation. The leakage from un-cuffed endotracheal intubation following intravenous induction also generate significant $\mathrm{N}_{2} \mathrm{O}$ contamination during the maintenance period, but not during the induction period. In brief, anesthesiologists performing these two procedures would possibly be susceptible to significant $\mathrm{N}_{2} \mathrm{O}$ contamination at different periods. Finally, cuffed intubation with intravenous induction or ventilation hood would significantly diminish the $\mathrm{N}_{2} \mathrm{O}$ contamination to the working personnel.

Several other factors would contribute significantly to $\mathrm{N}_{2} \mathrm{O}$ contamination during pediatric anesthesia. The size selection of endotracheal tubes were dependent on the age or body size of the patients under anesthesia. If caliber of the tubes were too small for the trachea or the position of tubing was inappropriate, $\mathrm{N}_{2} \mathrm{O}$ might leak from the patients' throat, evidenced in the results of intravenous induction followed with uncuffed intubation (Table 1).

The ambient air-exchange rate in the operating rooms would apparently modify $\mathrm{N}_{2} \mathrm{O}$ contamination to the anesthesiologists. In this study, the air exchange rate of more than 25 times per hour has been maintained to reduce the waste $\mathrm{N}_{2} \mathrm{O}$ gas to negligible between different operations or measurements. However, ambient air exchange was relatively inefficient to reduce $\mathrm{N}_{2} \mathrm{O}$ pollution to the anesthesiologist, as they were close to the leakage source from patients.

Miran 1B2 has been demonstrated as a convenient and reliable instrument for detecting trace levels of various waste anesthetics and with minimal interference between different anesthetics. It was shown with satisfactory results while conducting real time measurements in other studies ${ }^{22,23,25)}$. The region of measurement, around breathing zone of the anesthesiologist in this study, was not required by the $\mathrm{NIOSH}^{1)}$. Measurement around the breathing zone seemed to provide appropriate information of individual exposure. Alternative sites of measurement have been suggested pertinent that when the exposure concentration was less than $35 \mathrm{ppm}$, the $\mathrm{N}_{2} \mathrm{O}$ at the level of anesthetic machine shelf was correlated well with personal sampling ${ }^{25,26)}$. In this study, the $\mathrm{N}_{2} \mathrm{O}$ contamination was most apparent during induction period while the anesthesiologist was close to the patients. Slight underestimation in $\mathrm{N}_{2} \mathrm{O}$ exposure by environmental monitoring than by personal sampling was expected. If the measurement was conducted in multiple environmental points around the respiratory zone, this would approximate the results performed by personal monitoring. However, the results provided by convenient Miran environmental measurement would provide practical $\mathrm{N}_{2} \mathrm{O}$ exposure level to the anesthesiologist at daily basis. Further studies are suggested to elucidate the difference between this method and those of personal monitoring.

In conclusion, the anesthesiologist was exposed significantly to excessive $\mathrm{N}_{2} \mathrm{O}$ during various pediatric anesthesia. In them, mask general anesthesia provided most severe exposure, while mask induction followed with cuffed 
endotracheal intubation or intravenous induction followed with uncuffed endotracheal incubation also provided excessive pollution. For the safety of the anesthesiologists, mask anesthesia accompanied with a ventilation hood and active suction is suggested as the alternative for simple mask general anesthesia. Without suitable intervention, the anesthesiologists would be exposed most significantly during mask general anesthesia and appropriate caution or prevention is recommended.

\section{Acknowledgments}

We are indebted to the suggestions and technical support of Dr. CM Lin in the National Taiwan University, Dr. SL Hwang of the National Yang Ming University, and Dr. Takyu Lee of the Veteran General Hospitals. The ventilation hood with active suction has been kindly offered by Dr. Senkou Tsai. This work was supported partly by the Department of Health, Taiwan (DOH82.HP.09.2SO2).

\section{References}

1) NIOSH (1977) Criteria for a Recommended Standards. In: Occupational exposure to waste anesthetic gases and vapors, No. 77-140. DHEW, Cincinnati, Ohio.

2) Vaisman $A$ (1967) Working conditions in surgery and their effects on the health of anesthesiologists. Eskp Khir Anesthesiol 3, 44-9 (in Russian).

3) Kugel G, Norris LH, Zive MA (1989) Nitrous oxide and occupational exposure: It's time to stop laughing. Anesth Prog 36, 252-7.

4) Kugel G, Letelier C, Atallah M, Zive M (1986) Chronic low level nitrous oxide exposure and infertility. J Dent Res 313, Abst. 1057.

5) Tannenbaum TN, Goldberg RJ (1985) Exposure to anesthetic gases and reproductive outcome. J Occup Med 27, 659-68.

6) Cohen EN, Brown BW, Bruce DL (1974) Occupational disease among operating room personnel: a national study. Anesthesiology 41, 321-40.

7) Sardas S, Cuhruk H, Karakaya AE, Akakurt Y (1990) Sister-chromatid exchanges in operating room personnel. Mutat Res 279, 117-20.

8) Lamberti L, Bigatti P, Ardito G, Armellino F (1989) Chromosome analysis in operating room personnel. Mutagenesis 4, 95-7.

9) Karelova J, Jablonicka A, Gavora J, Hano L (1992) Chromosomal and sister chromatid exchange analysis in peripheral lymphocytes, and mutagenicity of urine in anesthesiology personnel. Int Arch Occup Environ Health 64, 303-6.

10) Reitz M, Coen R, Lanz E (1994) DNA single-strand breaks in peripheral lymphocytes of clinical personnel with occupational exposure to volatile inhalation anesthetics. Environ Res 65, 12-21.

11) Chang WP, Lee SR, Tu JR, Hseu SS (1996) Increased micronucleus formation in nurses with occupational nitrous oxide exposure in operating theaters. Environ Mol Mutagen 27, 263-70.

12) American Conference of Governmental Industrial Hygienists (ACGIH). 1989-1990 Documentation of the threshold limit values and biological exposure indices. 32, ACGIH, Cincinnati, OH. 10024-97-2.

13) American Conference of Governmental Industrial Hygienists (ACGIH). Draft report from the ACGIH Committee on nitrous oxide. Cincinnati, $\mathrm{OH}$.

14) Center for Disease Control, CDC (1994) Control of nitrous oxide in dental operatories. Cincinnati, OH: U.S. Department of Health, Education, and Welfare, Public Health Service, National Institute of Occupational Safety and Health, DHEW Publ. No. 94-129.

15) Whitcher CE, Piziali R, Sher R, Tonn EM, Zimmerman DC (1975) Development and evaluation of methods for the elimination of waste anesthetic gases and vapors in hospitals. NIOSH Publication 75-137. US Department of HEW, Public Health Service, Cincinnati.

16) Tonn EM, Whitcher CE (1980) Scavenging of waste nitrous oxide in pediatric dental offices. J Int Assoc Dent Child 11, 41-6.

17) American National Standards Institute, ANSI (1982) American national standard for anesthetic equipment: scavenging systems for excess anesthetic gases. ANSI Z.79.11-1982. New York.

18) Hallonsen A (1982) Nitrous oxide scavenging in dental surgery: a comparison of the efficiency of different scavenging devices. Swed Dent J 6, 203-13.

19) Christensen JR, Vann WF, Linville DR (1985) Measurement of scavenged nitrous oxide in the dental operatory. Pediatr Den 7, 192-7.

20) Jacobs DE, Middendorf PJ (1986) Control of nitrous oxide exposure in dental operatories using local exhaust ventilation: a pilot study. Anesth Prog 33, 235-42.

21) Henry RJ, Primosch RE, Courts FJ (1992) The effects of various dental procedures and patient behaviors upon nitrous oxide scavenger effectiveness. Pediatr Dent 14, 19-25. 
22) Vean $\mathrm{AH}$, King $\mathrm{KJ}$ (1979) Measuring $\mathrm{N}_{2} \mathrm{O}$ levels in the dental operatory. ASDC J Dent Child 46, 22-7.

23) Badger GR, Robertson CW (1982) Nitrous oxide waste gas in the perodontic operatory. J Am Den Assoc 104, 480-1.

24) Ship JA (1987) A survey of nitrous oxide levels in dental offices. Arch Environ Health 42, 310-4.

25) Burkhart JE, Stobbe TJ (1990) Real-time measurement and control of waste anesthetic gases during veterinary surgeries. Am Ind Hyg Asso J 51, 640-5.
26) Schapera A (1993) An anesthesia mask gas-scavenging system. J Occup Med 35, 1138-41.

27) Azar I, Eisenkraft JB (1993) Waste anesthetic gas spillage and scavenging systems. In: Anesthesia equipment: Principles and applications. eds. by Ehrenwerth J, Eisenkraft JB, Mosby Publ.

28) Kaarakka P, Malischke PR, Kreul JF (1991) Alternative sites for measuring breathing zone nitrous oxide levels. Anesthesiol 55S, 139A. 